\title{
In silico promoter and expression analyses of rice Auxin Binding Protein 57 (ABP57)
}

\author{
Farah Afiqah Baharuddin ${ }^{1}$, Zhan Xuan Khong ${ }^{1}$, Zamri Zainal ${ }^{1,2}$ \& Noor Liyana Sukiran ${ }^{1^{*}}$ \\ ${ }^{1}$ Department of Biological Sciences and Biotechnology, Faculty Science and Technology, Universiti Kebangsaan Malaysia, 43600 UKM Bangi, \\ Selangor, Malaysia \\ ${ }^{2}$ Institute of Systems Biology, Universiti Kebangsaan Malaysia, 43600 UKM Bangi, Selangor, Malaysia \\ *Email: liyana@ukm.edu.my
}

\section{ARTICLE HISTORY}

Received: 13 April 2021

Accepted: 26 June 2021

Available online: 14 August 2021

\section{KEYWORDS}

abiotic stress

Auxin Binding Protein

expression analysis

promoter analysis

rice
ABSTRACT

Auxin Binding Protein 57 (ABP57) is one of the molecular components involved in rice response to abiotic stress. The ABP57 gene encodes an auxin receptor which functions in activating the plasma membrane $\mathrm{H}^{+}$-ATPase. Biochemical properties of ABP57 have been characterized; however, the function of $A B P 57$, particularly on stress and hormone responses is still limited. This study was conducted to understand the regulation of ABP57 expression under abiotic stress. Thus, in silico identification of cis-acting regulatory elements (CAREs) in the promoter region of ABP57 was performed. Several motifs and transcription factor binding site (TFBS) that are involved in abiotic stress such as ABRE, DRE, AP2/EREBP, WRKY and NAC were identified. Next, expression analysis of ABP57 under drought, salt, auxin (IAA) and abscisic acid (ABA) was conducted by reverse transcription-PCR (RT-PCR) to verify the effect of these treatments on ABP57 transcript level. ABP57 was expressed at different levels in the shoot and root under drought conditions, and its expression was increased under IAA and ABA treatments. Moreover, our results showed that ABP57 expression in the root was more responsive to drought, auxin and $A B A$ treatments compared to its transcript in the shoot. This finding suggests that $A B P 57$ is a drought-responsive gene and possibly regulated by IAA and ABA.

\section{Introduction}

As sessile organisms, plants adapt to the environment by maximizing the growth potential to escape stressful conditions or undergo growth reduction for survival (1). Drought promotes abscisic acid (ABA) synthesis, which subsequently initiates signal transduction and affects cellular responses to stress (2). ABA is involved in plant adaptation to abiotic stress, especially in regulating physiological responses such as root elongation and stomatal aperture (3). Additionally, ABA modulates root architecture under water scarcity by regulating root meristem function and root cell length (4). Plant physiological changes during stress conditions are regulated by ABA interactions with other hormones such as auxin, ethylene and jasmonate (3).

Gene expression is diverse among plant stages of development, tissues and response to external stimulus. A stress-responsive gene expression is regulated by specific sequences present at the promoter known as cisacting regulatory elements (CAREs). These regulatory elements served as motifs or binding sites for proteins called transcription factors (TFs), activating or repressing the expression of stress-responsive genes (5-7). For example, abscisic acid responsive element (ABRE) is involved in transcriptional responses induced by phytohormone $\operatorname{ABA}(5,8)$ and this element is recognized by ABA-RESPONSIVE ELEMENT BINDING PROTEIN (AREB) and ABRE BINDING FACTOR (ABF) (9-11). These TFs play a role in regulating plant response to osmotic stress such as drought and high salinity $(9,10)$.

Auxin is a key phytohormone that regulates various processes in plant growth, development and stress response $(12,13)$. Together with $\mathrm{ABA}$ and ethylene, auxins act as communication signals between roots and shoots in rice $(14,15)$. Auxin signaling is facilitated by AUXIN RESPONSE FACTORS (ARFs), which bind to the Aux/IAA motif and activate the transcription of auxininducible genes $(16,17)$. However, not all auxin responses employ this pathway, especially some rapid responses at the plasma membrane (18). This response involved another candidate of the auxin receptor, which is AUXIN BINDING PROTEIN 1 (ABP1). $A B P 1$ localizes mainly at the endoplasmic reticulum (ER), and it is involved in regulating the membrane potential at the plasma membrane $(18,19)$. 
Other than ABP1, another putative auxin receptor known as AUXIN BINDING PROTEIN 57 (ABP57) has been isolated from the shoot of rice (20). Apparently, this protein exists only in monocots such as Oryza sativa, Zea mays, Sorghum bicolor and Setaria viridis, but not in the dicot plant (21, 22). The binding of ABP57 to indole-3-acetic acid (IAA) leads to the activation of the plasma membrane $\mathrm{H}^{+}$-ATPase by direct interaction (21). Previously, a study showed that the ABP57 overexpression had increased the resistance of transgenic rice to drought stress (23). Moreover, the 35S::ABP57 transgenic Arabidopsis possessed root elongation changes and also restoration of root cells under drought and submergence conditions (24-26).

These previous studies suggest that $A B P 57$ is involved in abiotic stress and root development. However, more studies are needed to uncover the role of $A B P 57$ in plant development and stress response. To date, no information regarding ABP57 transcriptional regulation is available, particularly on the characterization of its promoter. Nevertheless, the effect of stress and hormone treatments on ABP57 expression has yet to be determined. Hence, the objectives of this study were to characterize the CAREs present at the promoter region of $A B P 57$ via in silico analysis and to determine the effect of osmotic stresses (drought and salt) and hormones (IAA and ABA) on the transcript level of $A B P 57$ in the rice at various time points.

By performing in silico promoter analysis, CAREs including transcription factor binding sites (TFBS) involved in stress response were identified. In addition, our expression analysis showed that ABP57 responds to drought, high salinity, auxin and ABA. It confirms that the presence of several motifs is required to activate ABP57 expression under these treatments. Taken together, our study provided insight into the transcriptional regulation of ABP57 under stress conditions.

\section{Materials and Methods}

\section{In silico promoter analysis}

The ABP57 (Gene ID: LOC_Os07g02970) promoter sequence (upstream of -1000 and 220 bp 5'-UTR) was obtained from Phytozome v12.1 (https://www.phytozome.net) (27). This promoter region was then analyzed in PLACE (https://dna.affrc.go.jp/PLACE/?action=newplace) (28), PlantCARE (http://bioinformatics.psb.ugent.be/webtools/plantcare/html) (29) and PlantPAN 3.0 (http://plantpan.itps.ncku.edu.tw/) (30) to identify cis-acting regulatory elements (CAREs) and transcription factor binding sites (TFBS). The function of TFs identified in these analyses was further examined in Oryzabase (https://shigen.nig.ac.jp/rice/oryzabase/). Only TFs involved in biotic and/or abiotic stress response were selected in this study.

\section{Plant materials and growth conditions}

The indica rice cV. IR64 and MR219 were obtained from the Malaysian Agricultural Research and Development Institute (MARDI). Drought treatment was conducted in a greenhouse with relative humidity was $85 \%$, and the maximum and minimum temperatures were $30{ }^{\circ} \mathrm{C}$ and $25{ }^{\circ} \mathrm{C}$ respectively. Salt, auxin and ABA treatments were conducted at $25{ }^{\circ} \mathrm{C}$ under $16 \mathrm{hr}$ light $/ 8 \mathrm{hr}$ dark in a temperature-controlled growth room. All experiments were performed at Plant Biotechnology Centre, Universiti Kebangsaan Malaysia (UKM).

\section{Drought treatments}

Drought treatment was conducted as per standard procedure (31). The seeds (cv. IR64) were soaked in distilled water for two days to break seed dormancy before they were sowed in a petri dish with wet cotton to allow germination. The 10-daysold rice seedlings were transferred into pots (D 12 $\mathrm{cm} \times \mathrm{H} 13 \mathrm{~cm}$ ) that contain mixed soils (topsoil: organic matter: sand with ratio $3: 2: 1)$. Five pots were prepared for each control and treatment, and each pot contained three seedlings. All seedlings were watered daily for three weeks before drought treatment begins. Control plants were watered continuously, whereas water withholding was imposed on treatment plants for four weeks. The mature leaf (L5) and root samples from three seedlings were collected weekly (Week 1, 2, 3 and 4). All samples were flash-frozen before total RNA extraction.

\section{Salt, auxin and abscisic acid treatments}

Seeds of rice (cv. MR219) were surface-sterilized with sodium hypochlorite for $15 \mathrm{~min}$ before they were soaked in distilled water for two days. Seeds were planted on moist cotton and they were grown for 10 days. These 10-days-old rice seedlings were used for salt $(\mathrm{NaCl})$, IAA and ABA treatments. The seedlings were transferred separately into $50 \mathrm{ml}$ centrifuge tubes containing $35 \mathrm{ml}$ of $250 \mathrm{mM} \mathrm{NaCl}$, $100 \mu \mathrm{M}$ IAA and $100 \mu \mathrm{M}$ ABA solutions respectively. In each tube, three seedlings were transferred and whole seedlings were soaked for 0,6 and $24 \mathrm{hrs}$. Three replicates were prepared in each treatment. The root and leaf (L3) samples were cut and flashfrozen in liquid nitrogen prior to total RNA isolation.

\section{Semi-quantitative expression analysis of ABP57}

To determine the expression pattern of ABP57 during osmotic stress and hormone treatments, RT-PCR was carried out. Total RNAs from the leaf and root were extracted using Trizol ${ }^{\circledR}$ Reagents (Thermo Scientific, USA) following the manufacturer's instruction. The quality and quantity of the total RNA were determined by a spectrophotometer (NanoDrop 1000, USA). DNase treatment was performed on $1 \mathrm{mg}$ of total RNA with RQ1 RNase-Free DNase (Promega Corp, USA) to ensure that RNA samples were free from genomic DNA contaminations. The cDNA was synthesized by reverse transcription on the total RNA using the SuperScript cDNA Synthesis kit (Invitrogen, Life Technologies, USA) following the manufacturer's instruction. The synthesized cDNA was then used as a template for PCR.

Two pairs of primers were used for PCR which are ABP57-specific (Forward: 5'ATGGCAGAGATTGTTAGTTC-3'; Reverse: 5'- 
CTAAAATTTCAGGCGCAGTA-3') and a housekeeping gene, U6 small nuclear RNA (U6 snRNA) that acts as an internal control (Forward: 5'TACAGATAAGATTAGCATGGCCC-3'; Reverse: 5'GGACCATTTCTCGATTTGTACGTG-3') (24, 25). The amplicon sizes were $1550 \mathrm{bp}$ and $60 \mathrm{bp}$, respectively. Amplification of ABP57 was performed using the GoTaq ${ }^{\circledR}$ Green Master Mix kit (Promega Corp. USA) with the following program: $95{ }^{\circ} \mathrm{C}$ for 2 min followed by 35 cycles of $\left(95{ }^{\circ} \mathrm{C}, 1\right.$ min; $58{ }^{\circ} \mathrm{C}$, $1 \mathrm{~min} ; 72{ }^{\circ} \mathrm{C}, 2.5 \mathrm{~min}$ ) and $72{ }^{\circ} \mathrm{C}$ for 5 min. Meanwhile, the following programme was performed for amplification of $U 6: 95^{\circ} \mathrm{C}$ for $2 \mathrm{~min}$ followed by 25 cycles of $\left(95{ }^{\circ} \mathrm{C}, 1 \mathrm{~min} ; 56^{\circ} \mathrm{C}, 1 \mathrm{~min}\right.$; $72{ }^{\circ} \mathrm{C}, 1 \mathrm{~min}$ ) and $72{ }^{\circ} \mathrm{C}$ for $5 \mathrm{~min}$. The PCR products were analyzed by $1.0 \%$ agarose gel electrophoresis, whereas the gel image was analyzed by ImageJ (https://imagej.nih.gov/ij) (32) for quantification of band densities (densitometry).

\section{Statistical analysis}

The mean data was recorded by taking average value and subjected to analysis of variance (ANOVA) by using the SAS programme version 9.4. The ANOVA was used to determine the variation for all parameters such as type of organ (leaf and root), genotypes and treatments. Mean comparisons were performed using Duncan's New Multiple Range Test (DNMRT). Differences among the treatments mean were considered statistically significant when the p-value is less than 0.01 (33). All data represent an average of three replicates and the standard error.

\section{Results}

\section{In silico analysis of the $A B P 57$ promoter}

Cis-acting regulatory elements (CAREs) of the promoter regions play a significant role in the transcriptional regulation of stress-inducible genes. To obtain an insight into the regulation of $A B P 57$ expression, in silico promoter analysis was conducted. Many CAREs were identified at the promoter of ABP57 (Table 1). Based on PLACE and PlantCARE databases, several motifs that are related to stress responses were found in the $A B P 57$ promoter, which include ABRE (ABA-responsive element), DRE (dehydration responsive element) and LTR (low temperature-responsive element). Besides that, motifs involved in hormone response such as EREBP (ethylene-responsive binding protein) and GARE (gibberellin-responsive element) were also present.

Several transcription factor binding sites (TFBS) available in the promoter region of ABP57 were listed in Table 1. This TFBS belong to TFs such as WRKY, MYB, MYC, bZIP (Basic Leucine Zipper), HD (Homeodomain)

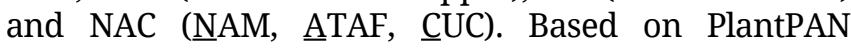
database search, binding sites for other TF families were also discovered, such as B3, bHLH (Basic HelixLoop-Helix), C2H2 Zinc Finger, GATA Zinc Finger, NF-YB (Nuclear Factor-Y Subunit B) and TCP (TEOSINTE BRANCHED 1, CYCLOIDEA, PCF1) (Table 2). The listed TFs in Table 2 are involved in stress response and this result suggests that they could be the regulator for $A B P 57$ during adverse conditions.

\section{$A B P 57$ expression pattern under drought and salt treatments}

Water withheld of the 4-weeks-old seedlings were carried out for four weeks, and expression patterns of $A B P 57$ under prolonged drought stress were determined (Fig. 1). The ABP57 transcript was slightly expressed in the leaf and root under normal conditions (Fig. 1A). During drought treatment, ABP57 was lowly expressed in the leaf during the first and second week, but its expression was increased dramatically at Week 3 and slightly decreased at Week 4 (Fig. 1B). ABP57 transcript was also observed in the untreated root; however, its expression level was significantly increased $(p \leq 0.01)$ at Week 2 of drought treatment and noticeably decreased at Week 3 and Week 4 (Fig. 1B). These results indicate that $A B P 57$ is expressed under normal conditions, but prolonged drought treatment has much induced $A B P 57$ expression in both leaf and root at different time points. $A B P 57$ was highly expressed in the leaf at Week 3, whereas the highest expression in the root can be seen at Week 2 of drought treatment.

On the other hand, ABP57 expression in the seedlings treated with high salinity $(250 \mathrm{mM} \mathrm{NaCl})$ was examined for 6 and $24 \mathrm{hrs}$. Our results showed that $A B P 57$ was expressed in the control but significantly reduced $(\mathrm{p} \leq 0.01)$ in the shoot and root after $6 \mathrm{hrs}$ of $\mathrm{NaCl}$ treatment (Fig. 2). After $24 \mathrm{hrs}$, the expression of $A B P 57$ in both of leaf and root was significantly lowered than its expression at $6 \mathrm{hrs}$. This result suggests that the expression of $A B P 57$ in the seedlings is suppressed by high salt concentration.

\section{Auxin and abscisic acid treatments induced ABP57 expression}

ABP57 acts as an auxin receptor and binds to IAA to activate the plasma membrane $\mathrm{H}^{+}$-ATPase by regulating proton $\left(\mathrm{H}^{+}\right)$translocation activity (21). To examine the effect of IAA treatment on ABP57 expression, we analyzed the $A B P 57$ transcript in the shoot and root of rice treated with this hormone. Our results showed that $A B P 57$ was induced after 6 hrs of IAA treatment in both shoot and root (Fig. 3A). The highest expression of $A B P 57$ in the leaf and root can be seen at $6 \mathrm{hrs}$ and 24 hrs of IAA treatment respectively. Although ABP57 expression in the root was gradually increased from 6 to $24 \mathrm{hrs}$, its transcript in the shoot was reduced at 24 hrs of IAA treatment (Fig. 3A). These results showed that although $A B P 57$ is responsive to exogenous auxin, it is preferably expressed in the root.

In this study, ABRE was found at the ABP57 promoter (Table 1) and ABP57 expression was increased under drought (Fig. 1). Thus, to determine whether ABP57 is affected by ABA, we examined its transcript in the rice seedling treated with a high $A B A$ concentration $(100 \mu \mathrm{M})$. The expression of $A B P 57$ was significantly reduced $(\mathrm{p} \leq 0.01)$ in both shoot and root after $6 \mathrm{hrs}$ of ABA treatment but was only increased after 24 hrs (Fig. 3B). Additionally, ABP57 expression in the root was significantly higher $(p<0.01)$ than in the shoot at both time points (Fig. 3B). This result showed that $A B P 57$ is responsive to exogenous ABA but only after 24 hrs of treatment and preferably expressed in the root. 
Table 1. Identification of cis acting regulatory elements (CAREs) and transcription factor binding sites (TFBS) at the ABP57 promoter through PLACE (28) and PlantCARE (29) databases.

\begin{tabular}{|c|c|c|c|}
\hline Binding site name & Position & Motif Sequence & Function \\
\hline CGCG box & $\begin{array}{l}+14,-14,+66,-66,+68,- \\
68,+181,-181\end{array}$ & VCGCGB & $\begin{array}{l}\text { involved in multiple signaling transduction pathways } \\
\text { (light signal perception, ethylene- and ABA-signaling) }\end{array}$ \\
\hline \multirow{2}{*}{$\begin{array}{l}\text { ABRE } \\
\text { (ABA Responsive Element) }\end{array}$} & +586 & ACGTG & \multirow{2}{*}{-ABA and dehydration response } \\
\hline & $+465,-465,-586$ & ACGT & \\
\hline \multirow{2}{*}{$\begin{array}{l}\text { DRE } \\
\text { (Dehydration Responsive Element) }\end{array}$} & +22 & ACCGAGA & \multirow{2}{*}{-ABA and drought response } \\
\hline & +170 & ACCGAC & \\
\hline AS-1 (Activation Sequence-1) element & $-259,-441$ & TGACG & $\begin{array}{l}\text { Induced by abiotic and biotic stresses, involved in } \\
\text { activation of genes by auxin and/or salicylic acid }\end{array}$ \\
\hline $\begin{array}{l}\text { LTRE } \\
\text { (Low Temperature Responsive Element) }\end{array}$ & +171 & CCGAC & Involved in cold and $\mathrm{ABA}$ response \\
\hline $\begin{array}{l}\text { GARE } \\
\text { (GA Responsive Element) }\end{array}$ & +767 & TAACAAR & GA response \\
\hline GCC core & $-34,-44,+50,+53,+62,-76$ & GCCGCC & Ethylene responsive element \\
\hline EREBP & +1105 & AWTTCAAA & Ethylene responsive element, related to senescence \\
\hline \multirow{3}{*}{ W-box } & $-395,+805$ & TTGACC & \multirow{3}{*}{-WRKY recognition site } \\
\hline & $-396,-442,+656,+802$ & TTGAC & \\
\hline & $\begin{array}{l}+20,-260,-396,-442,+646 \\
+657,-665,+686,-698,+806\end{array}$ & TGAC & \\
\hline \multirow{3}{*}{ MYB motif } & $+227,+238,-776$ & CNGTTR & \multirow{3}{*}{$\begin{array}{l}\text { - Response to dehydration stress } \\
\text {-MYB recognition site }\end{array}$} \\
\hline & -618 & AACGG & \\
\hline & +795 & CTAACCA & \\
\hline \multirow[t]{2}{*}{ MYC motif } & $\begin{array}{l}+262,-262,+360,-360, \\
+682,+726,-726,+737,- \\
737,+776,-776,+909,-909\end{array}$ & CANNTG & \multirow[t]{2}{*}{$\begin{array}{l}\text { MYC recognition site, involved in drought stress and } \\
\text { ABA response }\end{array}$} \\
\hline & -1060 & CACATG & \\
\hline bZIP motif & +315 & ACACNNG & bZIP recognition site, ABA response \\
\hline HD (Homeodomain) motif & $-657,-686$ & TGTCA & Binding site of OsBIHD1 \\
\hline $\mathrm{NAC}$ & +1060 & CATGTG & Dehydration stress \\
\hline
\end{tabular}

Table 2. Putative transcription factors (TFs) that may regulate $A B P 57$ expression. Their binding site was found at the $A B P 57$ promoter.

\begin{tabular}{|c|c|c|}
\hline $\begin{array}{l}\text { Transcription factor } \\
\text { family }\end{array}$ & Hit sequence & Inferred transcription factor \\
\hline \multirow{6}{*}{$\begin{array}{l}\text { AP2/ERF } \\
\text { AP2/EREBP }\end{array}$} & $\operatorname{tggCGGCG}$ & $\begin{array}{l}\text { OsERF67, OsERF3, SUB1B, OsERF106, OsERF92, OsERF53, OsERF99, OsERF91, OsERF88, OsERF95, } \\
\text { OsERF101, OsERF77, OsERF76 }\end{array}$ \\
\hline & $\begin{array}{l}\text { cGGCGGcg } \\
\text { cgCCGCCg }\end{array}$ & OsERF123, OsERF91, OsERF88, OsERF96, OsERF84 \\
\hline & $\begin{array}{l}\text { cCGCCGgc } \\
\text { gcCGGCGt }\end{array}$ & $\begin{array}{l}\text { SUB1B, OsERF106, OsERF76, OsERF50, OsERF72, OsERF3, OsERF68, OsERF99, OsERF91, OsERF95, } \\
\text { OsERF103, OsERF62, OsERF101, OsERF71, OsERF66, OsERF77 }\end{array}$ \\
\hline & $\begin{array}{l}\text { cCACCGact } \\
\text { tCACCGcct }\end{array}$ & DREB2C, DREB2A, DREB2E, OsERF42 \\
\hline & aCCGAC & $\begin{array}{l}\text { DREB2C, DREB2A, DREB1G, DREB2E, OsERF42, DREB1C, DREB1F, DREB1E, DREB2D, DREB1D, } \\
\text { OsERF28, DREB1B, DREB1H, DREB1A }\end{array}$ \\
\hline & AGCCGcc & EREBP1 \\
\hline B3 & GCATG & IDEF1 (IRON DEFICIENCY BINDING FACTOR 1) \\
\hline bHLH & cccACTTGa & OsbHLH110 \\
\hline \multirow[t]{2}{*}{$\mathrm{C} 2 \mathrm{H} 2$ zinc finger } & cACACTa & $\begin{array}{l}\text { ZFP252 (ZINC FINGER PROTEIN 252), BSRD1 (BROAD SPECTRUM RESISTANCE DIGU 1), DRZ1 } \\
\text { (DROUGHT RESPONSIVE ZINC FINGER PROTEIN 1) }\end{array}$ \\
\hline & tTCACTc & ZFP182, ZFP179, \\
\hline \multirow{2}{*}{ GATA zinc finger } & $\begin{array}{l}\text { tcTGATCac } \\
\text { ctGATCAct }\end{array}$ & CGA1 (CYTOKININ GATA TRANSCRIPTION FACTOR 1) \\
\hline & $\begin{array}{l}\text { acAGATCagg } \\
\text { actGATCTgt }\end{array}$ & OsGATA4 \\
\hline Homeodomain TALE & $\begin{array}{l}\text { TGACC } \\
\text { CGTCA } \\
\text { GGTCA } \\
\text { TGACA } \\
\text { AGTCA }\end{array}$ & HOMEOBOX1 \\
\hline \multirow[t]{2}{*}{ Myb/SANT } & $\begin{array}{l}\text { taGATTCtta } \\
\text { cagGAATCa }\end{array}$ & OsDLN196 \\
\hline & TAACAaа & GAMYB (GIBERELLIN-MYB) \\
\hline $\mathrm{NAC} / \mathrm{NAM}$ & $\begin{array}{l}\text { ggGTCAAtt } \\
\text { ttTTGACcc }\end{array}$ & ONAC10, ONAC88, NAC4, ONAC58, ONAC122, ONAC103, ONAC131, NAC5 \\
\hline \multirow{2}{*}{ WRKY } & $\begin{array}{l}\text { ggGTCAAt } \\
\text { tTTGACcc }\end{array}$ & $\begin{array}{l}\text { WRKY9, WRKY1, WRKY102, WRKY107, WRKY77, WRKY10, WRKY11, WRKY12, WRKY14, WRKY27, } \\
\text { WRKY26, WRKY16, WRKY17, WRKY39, WRKY66, WRKY42, WRKY71, WRKY20, WRKY13, WRKY51, WRKY3, } \\
\text { WRKY32, WRKY36, WRKY37, WRKY80, WRKY121, WRKY6, WRKY11, WRKY43, WRKY49, WRKY67, } \\
\text { WRKY68, WRKY8, WRKY5, WRKY7, WRKY29, WRKY31, WRKY73, WRKY28, WRKY76, WRKY25, WRKY47, } \\
\text { WRKY94, WRKY2, WRKY57, WRKY90, WRKY62, WRKY72 }\end{array}$ \\
\hline & atcGTCAAca & $\begin{array}{l}\text { WRKY111, WRKY9, WRKY94, WRKY51, WRKY1, WRKY11, WRKY12, WRKY14, WRKY15, WRKY17, WRKY19, } \\
\text { WRKY2, WRKY20, WRKY22, WRKY25, WRKY44, WRKY27, WRKY29, WRKY3, WRKY31, WRKY32, WRKY36, } \\
\text { WRKY37S, WRKY39, WRKY43, WRKY46, WRKY47, WRKY48, WRKY49, WRKY52, WRKY54, WRKY57, } \\
\text { WRKY66, WRKY67, WRKY68, WRKY69, WRKY73, WRKY74, WRKY102, WRKY8, WRKY90, WRKY116, } \\
\text { WRKY80, WRKY84, WRKY113, WRKY115, WRKY97, WRKY121, WRKY26, WRKY6, WRKY107 }\end{array}$ \\
\hline TCP & $\begin{array}{l}\text { GGTCC } \\
\text { GGGCC } \\
\text { GGCCC }\end{array}$ & PCF5 (PROLIFERATING CELL FACTOR 5), PCF8, PCF3 \\
\hline
\end{tabular}



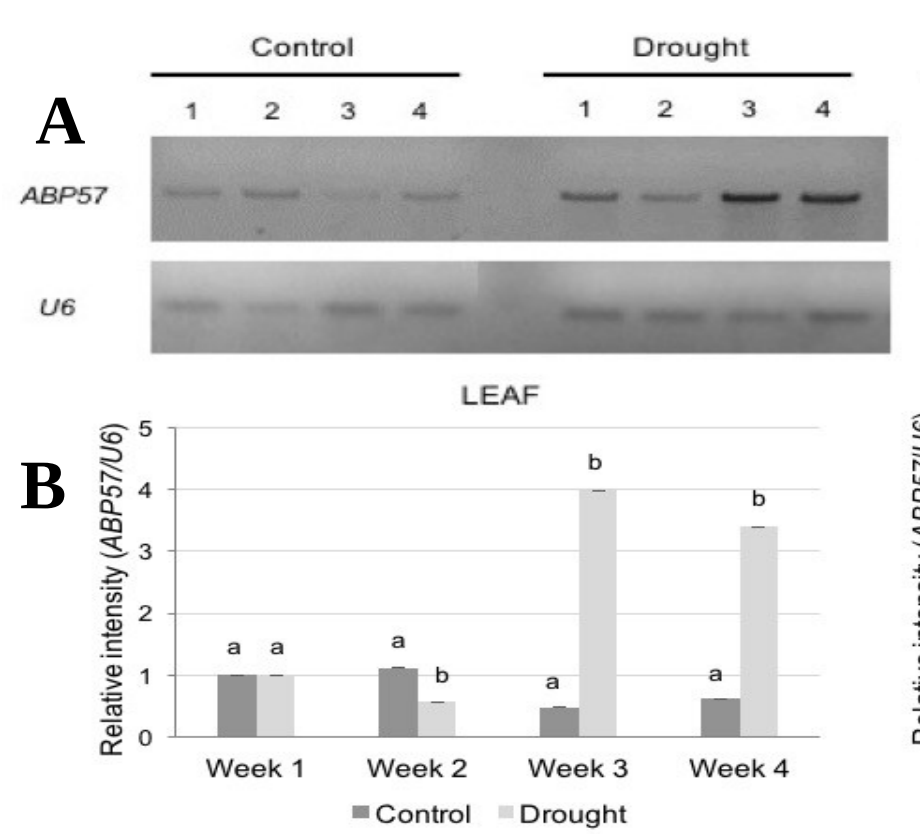
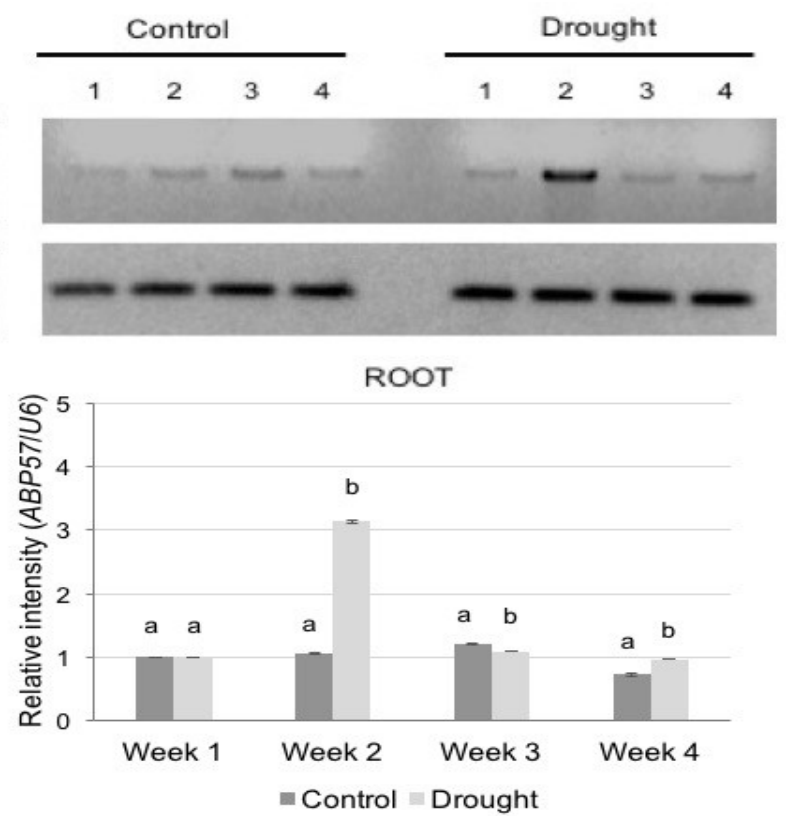

Fig. 1. (A) Semi-quantitative RT-PCR analysis in the leaf and root under drought conditions. Numbers 1 to 4 indicated the week of drought treatment. (B) The expression level of ABP57 in the leaf (left) and the root (right) was normalized to U6. Different letters indicate significant difference based on comparison using DNMRT at $\mathrm{p} \leq 0.01$.

\section{Discussion}

The biochemical properties of ABP57 have been characterized before $(20,21)$, but the molecular characterization of this gene is still limited. The overexpression of ABP57 in Arabidopsis and rice had increased their tolerance to high salt and drought, respectively $(23,25)$. These studies suggested that $A B P 57$ is required during the osmotic stress response. Therefore, to obtain more insight into the regulation of ABP57 expression during abiotic stress, we analyzed the ABP57 promoter in silico and its transcript changes under drought, salt, IAA and ABA treatments.

Promoter manipulation is one of the tools used in crop improvement, including stress response (34). It is known that different TFs attach to the promoter of stress-inducible genes in response to abiotic or biotic stresses. Indeed, several types of CAREs are essential in regulating the expression of droughtresponsive genes (35). Thus, identifying CAREs at the promoter of a stress-related gene will help in understanding its expression regulation. In this study, several CAREs involved in stress response

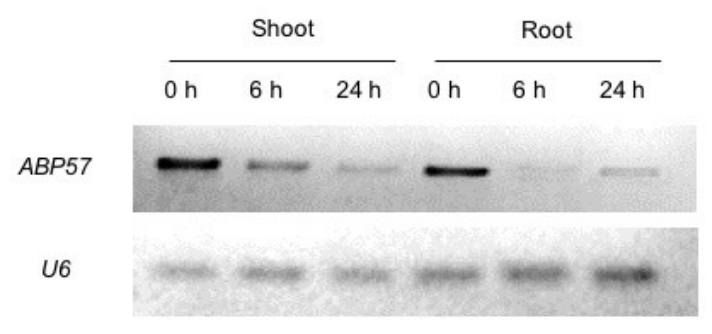

were identified at the $A B P 57$ promoter region, such as ABRE, DRE, LTR and others. ABRE contains an ACGT core, which is crucial for DREB2A expression in Arabidopsis $(8,35,36)$ and a recognition site for plant bZIP transcription factors during drought conditions (37). The DRE motif consists of a core sequence A/GCCGAC, which is a conserved sequence in the promoter region of DREBs' direct target genes (38). Meanwhile, the LTR element (CCGAC) is necessary for the activation of low temperature-responsive genes during cold stress $(39,40)$. These results suggest that ABP57 might respond to various environmental stimulus such as water deficit and low temperature.

Besides that, many TF binding sites related to abiotic stress response present at the ABP57 promoter. Osmotic stress activates ABA-independent and ABA-dependent signaling pathways, including TFs like DREB, WRKY, bZIP, MYC, MYB and NAC ( 3,8 , 41). These TFs attach to the cis-acting elements in the promoter and activate the transcription of secondary responsive genes, thus, increasing plant tolerance to stress $(41,42)$. The binding site of AP2/EREBP and WRKY was mainly found in the upstream region of ABP57. AP2/EREBPs regulate numerous abiotic stress

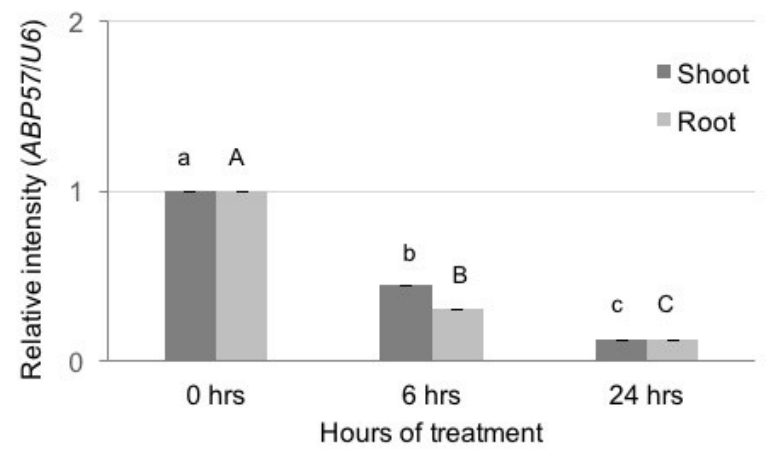

Fig. 2. Semi-quantitative RT-PCR analysis in the shoot and the root under salt treatment. The expression level of ABP57 was normalized to U6. Different letters indicate significant difference based on comparison using DNMRT at $\mathrm{p} \leq 0.01$. Capital letters and small letters indicate differences among root and shoot samples, respectively. 

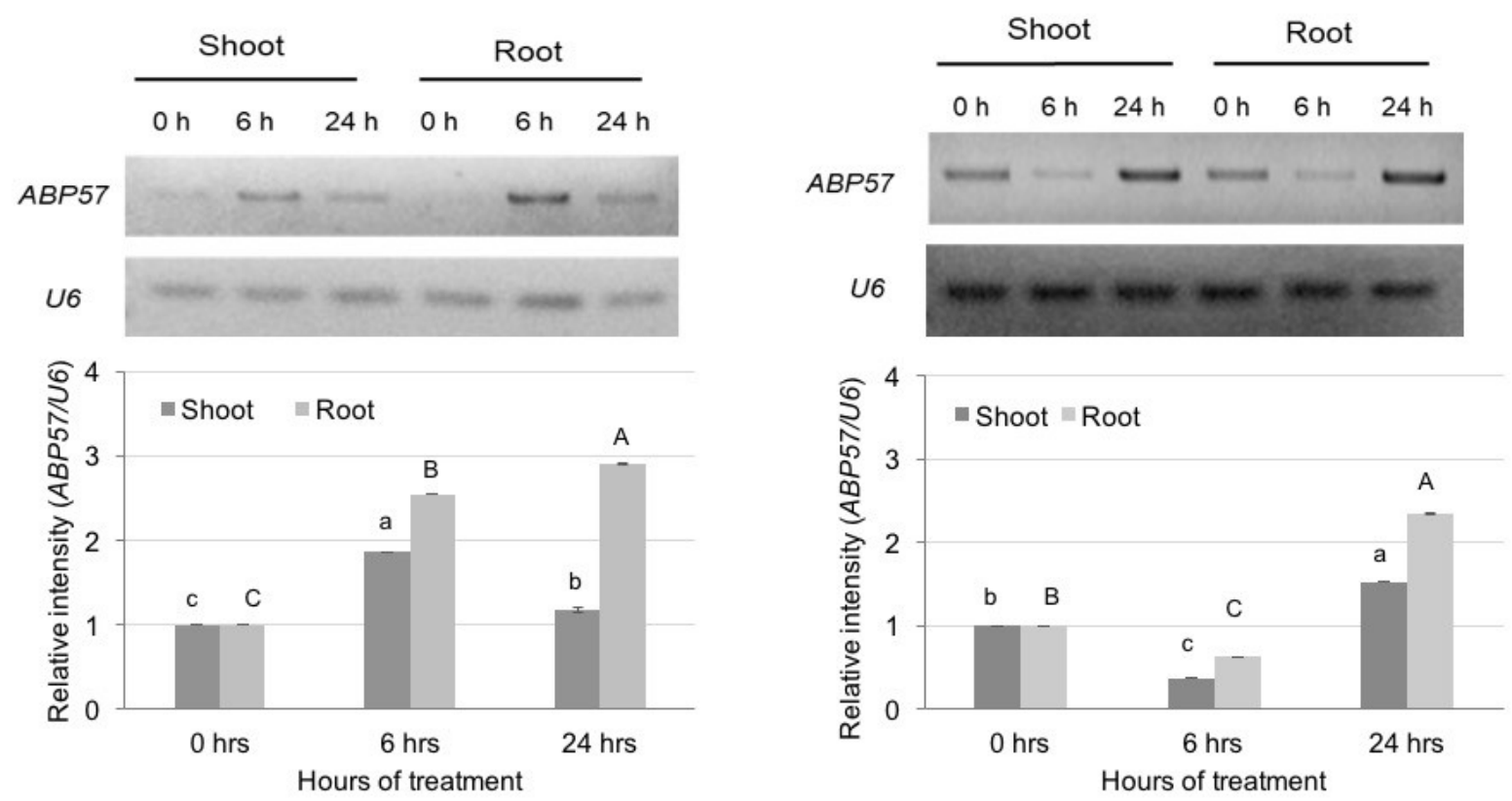

Fig. 3. Semi-quantitative RT-PCR analysis in the shoot and the root under (A) auxin and (B) abscisic acid. The expression level of ABP57 was normalized to U6. Different letters indicate significant difference based on comparison using DNMRT at $\mathrm{p} \leq 0.01$. Capital letters and small letters indicate differences among root and shoot samples, respectively.

and hormone responses, and one of its family members, DREB, is a major regulator in plant response to cold, drought, heat and salt (42). Meanwhile, WRKY proteins recognize and bind to Wbox, which is also essential in activating stressresponsive genes (43). With these findings, we suggest that $A B P 57$ might be regulated by ABA, and could be the direct or indirect target gene for TFs such as DREB, WRKY and bZIP during stress response. Therefore, further studies need to be carried out to determine the interaction between $A B P 57$ and its putative transcriptional regulator.

Both ABRE and DRE were found at the ABP57 promoter, and these elements regulate the expression of ABA-, osmotic- and drought-responsive genes (36, 38 ). It suggests that $A B P 57$ could be involved in ABA and osmotic stress response. Therefore, to confirm this hypothesis, ABP57 transcript levels under drought, high salinity and ABA treatments were analyzed. Our results showed that $A B P 57$ expression is induced by drought and ABA preferably in the root, but suppressed by salt treatment, indicating that $A B A$ could regulate $A B P 57$ involvement in drought response. Based on Rice eFP Browser, ABP57 expression is not highly induced by drought, salt, nor cold conditions (http://bar.utoronto.ca/eplant_rice/). Although our result contradicted the expression profile in the database, it might happen because different types of samples were used. In addition, the difference maybe because of the time point of the study, as results showed differential expression at different time point. The expression of ABP57 in this study might be affected by the stage of rice development, types of tissues, duration of drought treatment and concentrations of $\mathrm{NaCl}$ and $\mathrm{ABA}$.

Although the AuxRE motif was absent at the promoter region of $A B P 57$, we speculated that auxin still could affect $A B P 57$ expression. It is because other than ARF-mediated transcription, auxin response can also be modulated by an additional signaling pathway (44). Under IAA treatment, the $A B P 57$ transcript level was higher in the root compared to the shoot. This result suggests that ABP57 is induced by auxin and preferentially expressed in the root. The high concentration of exogenous IAA may accelerate the binding of ABP57 to auxin and consequently, may elicit an auxin response of rice plasma membrane (21). Furthermore, the ABP57 response to auxin might be distinct from ARFmediated transcription and might involve different regulation of gene transcriptional activation and post-transcription $(17,45,46)$. Besides, plant response to auxin also depending on auxin concentrations and the types of cells and tissues (46).

\section{Conclusion}

In this study, we reported the cis-acting regulatory elements available at the promoter region of $A B P 57$, as well as the effect of drought, salt, auxin and ABA treatments on $A B P 57$ expression patterns at various time points. In silico promoter analysis showed several CAREs essential in stress response were identified, revealing the possible transcriptional regulation of ABP57 under abiotic stress and hormone treatments. Additionally, our expression analysis confirmed that $A B P 57$ is a droughtresponsive gene and may be involved in the root response to drought stress, possibly under auxin and ABA regulation. Drought response in plants involved regulation of gene expression and crosstalk among hormone signaling pathways. Therefore, the ABP57 loss-of-function mutant can be studied to further characterize the role of $A B P 57$ in abiotic stress and hormone response signaling pathways.

\section{Acknowledgements}

This project was supported by the Ministry of Education, Malaysia via Fundamental Research Grant 
(Grant No. FRGS/1/2016/STG03/UKM/02/3). We would like to thank MARDI Seberang Prai for providing the seeds, and Universiti Kebangsaan Malaysia (UKM) for providing the facilities to carry out this study.

\section{Authors' contributions}

FAB performed expression and statistical analyses, and wrote the manuscript. KZX performed expression analysis. ZZ designed the experiment and wrote the manuscript. NLS designed the experiment, performed in silico promoter analysis and wrote the manuscript. All authors read and approved the final manuscript.

\section{Conflict of interests}

The authors do not have any conflict of interest to declare.

\section{References}

1. Kohli A, Sreenivasulu N, Lakshamanan P, Kumar PP. The phytohormone crosstalk paradigm takes center stage in understanding how plants respond to abiotic stresses. Plant Cell Rep. 2013; 32(7): 945-57. https://doi.org/10.1007/s00299-0131461-y

2. Ng LM, Melcher K, Teh BT, Xu HE. Abscisic acid perception and signaling: Structural mechanisms and applications. Acta Pharmacol Sin. 2014;35:567-84. https://doi.org/10.1038/aps.2014.5

3. Sah SK, Reddy KR, Li J. Abscisic acid and abiotic stress tolerance in crop plants. Front. Plant Sci. 2016;7(571):1-26. https://doi.org/10.3389/fpls.2016.00571

4. Harris, JM. Abscisic acid: Hidden architect of root system $\begin{array}{llll}\text { structure. } & \text { Plants } & \text { (Basel.) } & \text { 2015;4(3):548-72. }\end{array}$ https://doi.org/10.3390/plants4030548

5. Gómez-Porras JL, Riaño-Pachón DM, Dreyer I, Mayer JE, Mueller-Roeber B. Genome-wide analysis of ABA-responsive elements $\mathrm{ABRE}$ and $\mathrm{CE} 3$ reveals divergent patterns in Arabidopsis and rice. BMC Genomics. 2007;8(260) https://doi.org/10.1186/1471-2164-8-260

6. Zou C, Sun K, Mackaluso JD, Seddon AE, Jin R, Thomashow MF, Shiu S-H. Cis-regulatory code of stress-responsive transcription in Arabidopsis thaliana. Proc Nat Acad USA. 2011; 108(36): 14992-97. https://doi.org/10.1073/pnas.1103202108

7. Hernandez-Gracia CM, Finer JJ. Identification and validation of promoters and cis-acting regulatory elements. Plant Sc. 2014;218:109-19. https://doi.org/10.1016/j.plantsci.2013.12.007

8. Hobo T, Asada M, Kowyama Y, Hattori T. ACGT-containing abscisic acid response element (ABRE) and coupling element 3 (CE3) are functionally equivalent. Plant J. 1999;19(6):679-89. https://doi.org/10.1046/j.1365-313x.1999.00565.x

9. Choi HI, Hong JH, Ha JO, Kang JY, Kim SY. ABFs, a family of ABA-responsive element binding factors. J Biol Chem. 2000;275(3):1723-30. https://doi.org/10.1074/jbc.275.3.1723

10. Uno Y, Furihata T, Abe H, Yoshida R, Shinozaki K, YamaguchiShinozaki K. Arabidopsis basic leucine zipper transcription factors involved in an abscisic acid-dependent signal transduction pathway under drought and high-salinity conditions. Proc Nat Acad. USA. 2000;97(21):11632-37. https://doi.org/10.1073/pnas.190309197

11. Singh D, Laxmi A. Transcriptional regulation of drought response: a tortuous network of transcriptional factors. Front Plant Sci. 2015;6:895. https://doi.org/10.3389/fpls.2015.00895

12. Zhao, Y. Auxin biosynthesis and its role in plant development. Annu Rev Plant Biol. 2010;61:49-64. https://doi.org/10.1146/annurev-arplant-042809-112308
13. Liu J, Rowe J, Lindsey K. Hormonal crosstalk for root development: A combined experimental and modeling perspective. Front Plant Sci. 2014;5(116):1-8. https://doi.org/10.3389/fpls.2014.00116

14. Xu W, Jia L, Shi W, Liang J, Zhou F, Li Q, Zhang J. Abscisic acid accumulation modulates auxin transport in the root tip to enhance proton secretion for maintaining root growth under moderate water stress. New Phytol. 2013;197(1):139-50. https://doi.org/10.1111/nph.12004

15. Rowe JH, Topping JF, Liu J, Lindsey K. Abscisic acid regulates root growth under osmotic stress conditions via an interacting hormonal network with cytokinin, ethylene and auxin. New Phytol. 2016;211(1):225-39. https://doi.org/10.1111/nph.13882

16. Abel S, Theologis A. Early genes and auxin action. Plant Physiol. 1996;111:9-17. https://doi.org/10.1104/pp.111.1.9

17. Leyser, O. Auxin signalling. Plant Physiol. 2018;176(1):465-79. https://doi.org/10.1104/pp.17.00765

18. Sauer M, Kleine-Vehn J. Auxin Binding Protein 1: The outsider. Plant Cell. 2011;23(6):2033-43. https://doi.org/10.1105/tpc.111.087064

19. Yamagami M, Haga K, Napier RM, Iino M. Two distinct signaling pathway participate in auxin-induced swelling of pea epidermal protoplast. Plant Physiol. 2004;134:735-47. https://doi.org/10.1104/pp.103.031294

20. Kim YS, Kim D, Jung J. Isolation of a novel auxin receptor from soluble fractions of rice (Oryza sativa L.) shoots. FEBS Letters. 1998;438(3):241-44. 5793(98)01307-6

https://doi.org/10.1016/S0014

21. Kim YS, Min JK, Kim D, Jung J. Soluble auxin-binding protein, ABP57 purification with anti-bovine serum albumin antibody and characterization of its mechanistic role in the auxin effect on plant plasma membrane $\mathrm{H}^{+}$-ATPase. I Biol Chem. 2001;276(14):10730-36. https://doi.org/10.1074/jbc.M009416200

22. Lee K, Kim MI, Kwon YJ, Kim M, Kim YS, Kim D. Cloning and characterization of a gene encoding ABP57, a soluble auxinbinding protein. Plant Biotechnol Rep. 2009;3:293-99. https://doi.org/10.1007/s11816-009-0101-z

23. Kamarudin ZS, Shamsudin NAA, Che Othman MH, Shakri T, Tan LW, Sukiran NL, Md Isa N, Ab Rahman Z, Zainal Z. Morpho-physiology and antioxidant enzyme activities of transgenic rice plant overexpressing ABP57 under reproductive stage drought condition. Agronomy 2020; 10(1530):1-14. https://doi.org/10.3390/agronomy10101530

24. Tan LW, Ab Rahman Z, Goh HH, Hwang DJ, Ismail I, Zainal Z. Production of transgenic rice (indica cv. MR219) overexpressing ABP57 gene through Agrobacterium-mediated transformation. Sains Malaysiana 2017;46:703-11. https://doi.org/10.17576/jsm-2017-4605-04

25. Tan LW, Tan CS, Ab Rahman Z, Hossein HM, Goh HH, Ismail I, Zainal Z. Overexpression of Auxin Binding Protein 57 from rice (Oryza sativa L.) increased drought and salt tolerance in transgenic Arabidopsis thaliana. IOP Conf. Ser.: Earth Environ Sci. 2018;197:1-9. https://doi.org/10.1088/1755$1315 / 197 / 1 / 012038$

26. Zambrose ZA, Mohd Roszelin SA, Mohd Hazbir NA, Chew BL, Jasmali SS, Wan Yahya WA, Md Isa N. Effect of rice Auxin Binding Protein 57 (OsABP57) overexpression in response to flooding. $\quad$ 2020;125-33. https://doi.org/10.17265/21616264/2020.03.001

27. Goodstein DM, Shu S, Howson R, Neupane R, Hayes RD, Fazo J, Mitros T, Dirks W, Hellsten U, Putnam N, Rokhsar DS Phytozome: a comparative platform for green plant genomics. 2012;40:1178-86. https://doi.org/10.1093/nar/gkr944

28. Higo K, Ugawa Y, Iwamoto M, Korenaga T. Plant cis-acting regulatory DNA elements (PLACE) database. Nucleic Acids Res. 1999;27(1):297-300. https://doi.org/10.1093/nar/27.1.297

29. Lescot M, Dehais P, Thijs G, Marchal K, Moreau Y, Van de Peer Y, Rouze P, Rombauts. PlantCARE, a database of plant cisacting regulatory elements and a portal to tools for in silico analysis of promoter sequences. Nucleic Acids Res. 2002;30(1):325-27. https://doi.org/10.1093/nar/30.1.325

30. Chow CN, Lee TY, Hung YC, Li GZ, Tseng KC, Liu YH, Kuo PL, Zheng HQ, Chang WC. PlantPAN3.0: a new and updated 
resource for reconstructing transcriptional regulatory networks from ChIP-seq experiments in plants. Nucleic Acids Res. 2019;8(47):1155-63. https://doi.org/10.1093/nar/gky1081

31. Baharuddin FA, Zainal Z, Sukiran NL. Morphological changes analysis of rice cv. IR64 under drought stress. AIP Conference Proceedings. https://doi.org/10.1063/1.5111242 2019;2111(1):040003.

32. Rueden CT, Schindelin J, Hiner MC, DeZonia BE, Walter AE, Arena ET, Eliceiri KW. ImageJ2: ImageJ for the next generation of scientific image data. BMC Bioinformatics. 2017;18(529):126. https://doi.org/10.1186/s12859-017-1934-Z

33. Duncan DB. Multiple range and multiple F-tests. Biometrics. 1955;11(1):1-42.

34. Singhal P, Jan AT, Azam M, Haq MR. Plant abiotic stress: A prospective strategy of exploiting promoters as alternative to overcome escalating burden. Front Life Sc. 2016;9(1):52-63. https://doi.org/10.1080/21553769.2015.1077478

35. Yamaguchi-Shinozaki K, Shinozaki K. Organization of cisacting regulatory elements in osmotic- and cold-stressresponsive promoters. Trends Plant Sci. 2006;10:88-94. https://doi.org/10.1016/j.tplants.2004.12.012

36. Kim JS, Mizoi J, Yoshida T, Fujita Y, Nakajima J, Ohori T, Todaka D, Nakashima K, Hirayama T, Shinozaki K, YamaguchiShinozaki K. An ABRE promoter sequence is involved in osmotic stress-responsive expression of the $D R E B 2 A$ gene, which encodes a transcription factor regulating droughtinducible genes in Arabidopsis. Plant Cell Physiol. 2011; 52(12): 2136-46. https://doi.org/10.1093/pcp/pcr143

37. Yang X, Yang YN, Xue LJ, Zou MJ, Liu JY, Chen F, Xue HW. Rice ABI5-Like1 regulates abscisic acid and auxin responses by affecting the expression of ABRE-containing genes. Plant Physiol.

2011;156:1397-1409 https://doi.org/10.1104/pp.111.173427

38. Maruyama K, Sakuma Y, Kasuga M, Ito Y, Seki M, Goda H, Shimada Y, Yoshida S, Shinozaki K, Yamaguchi-Shinozaki K. Identification of cold-inducible downstream genes of the Arabidopsis DREB1A/CBF3 transcriptional factor using two microarray systems. Plant J. 2004; 38(6):982-93. https://doi.org/10.1111/j.1365-313X.2004.02100.x

39. Jiang C, Iu B, Singh J. Requirement of a CCGAC cis-acting element for cold induction of the BN115 gene from winter Brassica napus. Plant Mol Biol. 1996;30:679-84. https://doi.org/10.1007/BF00049344

40. Wang C, Gao G, Cao S, Xie Q, Qi H. Isolation and functional validation of the CmLOX08 promoter associated with signalling molecule and abiotic stress responses in oriental melon, Cucumis melo var. makuwa Makino. BMC Plant Biol. 2019;19:75-89. https://doi.org/10.1186/s12870-019-1678-1

41. Gujjar RS, Akhtar M, Singh M. Transcription factors in abiotic stress tolerance. Ind. J. Plant Physiol. 2014;19:306-16. https://doi.org/10.1007/s40502-014-0121-8

42. Xie Z, Nolan TM, Jiang H, Yin Y. AP2/ERF transcription factor regulatory networks in hormone and abiotic stress responses in Arabidopsis. Front Plant Sci. 2019;10(228):1-17. https://doi.org/10.3389/fpls.2019.00228

43. Eulgem T, Rushton PJ, Robatzek S, Somssich IE. The WRKY superfamily of plant transcription factors. Trends in Plant Sci. 2000; 5(5): 199-206. https://doi.org/10.1016/S1360 1385(00)01600-9

44. Powers SK, Strader LC. Regulation of auxin transcriptional responses. Dev Dyn. 2020; 249(4):483-95. https://doi.org/10.1002/dvdy.139

45. Teale WD, Paponov IA, Palme K. Auxin in action: signalling, transport and the control of plant growth and development. Nat Rev Mol Cell Biol. 2006;7:847-59. https://doi.org/10.1038/nrm2020

46. Paponov IA, Paponov M, Teale W, Menges M, Chakrabortee S, Murray JAH, Palme K. Comprehensive transcriptome analysis of auxin responses in Arabidopsis. Mol Plant. 2008;1(2):321-37. https://doi.org/10.1093/mp/ssm021

\section{Additional information}

Peer review information: Plant Science Today thanks Sectional Editor and the othe anonymous reviewers for their contribution to the peer review of this work.

Reprints and permissions information is available at https://horizonepublishing.com/journals/index.php/PST/open_access_policy

Publisher's Note: Horizon e-Publishing Group remains neutral with regard to jurisdictional claims in published maps and institutional affiliations.

To cite this article: Baharuddin F A, Khong Z X, Zainal Z, Sukiran N L. In silico promoter and expression analyses of rice Auxin Binding Protein 57 (ABP57). Plant Science Today. 2021;8(3):741-748. https://doi.org/10.14719/pst.2021.8.3.1208

Plant Science Today, published by Horizon e-Publishing Group, is covered by Scopus, Web of Science, BIOSIS Previews, Clarivate Analytics, etc. See https://horizonepublishing.com/journals/index.php/PST/indexing_abstracting 